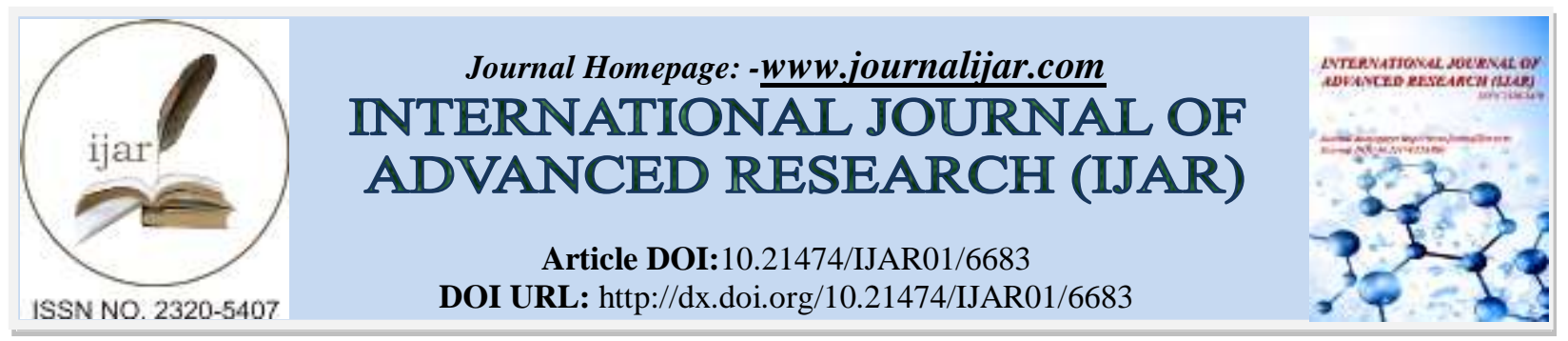

RESEARCH ARTICLE

\title{
CLINICAL AND BIOCHEMICAL STUDY OF FIBROBLAST GROWTH FACTOR 23 IN CHRONIC KIDNEY DISEASE.
}

\author{
Mohamed A. Alsenbesy ${ }^{1}$, Abdel-Kader A. Hashim ${ }^{1}$, Abdallah E. Mohamed ${ }^{2}$ and Mohammed H. Hassan ${ }^{3}$. \\ 1. Department of Internal Medicine- Faculty of Medicine- South Valley University, Qena-Egypt. \\ 2. Department of Clinical Pathology- Faculty of Medicine- South Valley University, Qena-Egypt. \\ 3. Department of Medical Biochemistry-Faculty of Medicine- South Valley University, Qena-Egypt.
}

\section{Manuscript Info}

Manuscript History

Received: 06 January 2018

Final Accepted: 08 February 2018

Published: March 2018

Keywords:-

Chronic kidney disease; FGF23; Bone

and minerals metabolism.

\begin{abstract}
Understanding the contributory role of increased fibroblast growth factor23 (FGF23) and secondary hyperparathyroidism to changes in minerals and bone metabolism among chronic kidney disease (CKD) patients is a challenge. So the present study aimed to evaluate the role of FGF23 in CKD of various grades and potential utility for early diagnosis of disturbed bone and mineral metabolism among such patients. This hospital based-cross sectional study has been conducted on $100 \mathrm{CKD}$ patients of various grades. Colorimetric assays of serum urea, creatinine, phosphorous and calcium, while, ELISA assays of parathormone hormone (PTH) and FGF23, were done to all included patients. The overall results showed frequent abnormally high serum FGF23 among CKD grade 3 and 4 compared to other grades. Also there was significant positive correlation between the serum FGF234 levels and the CKD grade $(\mathrm{r}=0.21, p=0.03)$. Significant positive correlations between serum levels of FGF23 vs. both urea and PTH $(\mathrm{r}=0.19, \mathrm{p}=0.04$ and $\mathrm{r}=0.31, \mathrm{p}=0.002$ respectively) with significant negative correlations between serum FGF23 levels vs. both total calcium and eGFR ( $\mathrm{r}=-0.21, \mathrm{p}=0.02$ and $\mathrm{r}=-0.39, \mathrm{p}=0.0001$ respectively). There were non-significant correlations between serum FGF23 and age, weight, height, BMI and phosphorous ( $>00.05$ ). FGF23 is better negative than positive predictive biomarker for calcium and phosphorous disturbances in CKD patients at cut off point 2.9 and $3.1 \mathrm{pg} / \mathrm{ml}$ respectively. In conclusion, FGF23 is an emerging biomarker in CKD and its follow up measurement could be helpful for early diagnosis of CKD-MBD.
\end{abstract}

Copy Right, IJAR, 2018,. All rights reserved.

\section{Introduction:-}

Chronic kidney disease (CKD) is one of the widely spread disorder all over the world with significant complications including early death (Wolf, 2012). Chronic kidney disease-mineral and bone disorder (CKD-MBD) involves the occurrence of calcium $(\mathrm{Ca})$, phosphorous $\left(\mathrm{PO}_{4}\right)$, parathormone hormone $(\mathrm{PTH})$ and vitamin $\mathrm{D}$ metabolism disturbances with turnover of bones, mineralization, cardiovascular or soft tissue calcification in relation to CKD (Moe et al.,2006). CKD-MBD characterized by lack of phosphate clearance, with decreased calcitriol (1, 25(OH) 2D3) and increased resorption of bone (Silver et al., 2012). The pathophysiology of CKD-MBD is a still conflicting 
as regard initiation, exacerbation or sequence of events involved (Diniz and Frazão, 2013). Fibroblast growth factor 23 (FGF-23) is a $32 \mathrm{KDa}$ hormone, mainly produced by osteoblasts and osteocytes (Liu et al., 2006).

FGF-23 binds to FGF receptor 1 (FGFR1)-Klotho complex in kidney with subsequent induction of phosphaturia and suppression of $1,25(\mathrm{OH})_{2} \mathrm{D} 3$ synthesis, and decreased synthesis and secretion of PTH (Komaba,2010; Nakai et al.,2010). FGF-23 is a bone derived hormone involved in phosphate homeostasis and recently proposed to be the initial protective response against phosphate retention in CKD (Diniz and Frazão, 2013), thus participate in understanding the dramatic changes in minerals and bone metabolism that occur in patients with CKD-MBD (Moe et al.,2006). Klotho deficiency which occurs early in CKD, participates in renal resistance to FGF23 with maladaptive rise in its serum level (Olauson et al.,2014).

The present study has been approached to study the possible role of FGF-23 in CKD-MBD and investigate its correlation to $\mathrm{CKD}$ stage, $\mathrm{Ca}, \mathrm{PO}_{4}, \mathrm{PTH}$, serum creatinine and estimated glomerular filtration rate (eGFR), so that can offers additional therapeutic strategies regarding the management of CKD-MBD.

\section{Materials and methods:- \\ Participants and data collection}

A cross sectional - hospital based study has conducted on 100 patients with CKD admitted to Internal Medicine Department of University Hospitals- South Valley University- Qena- Egypt, after approval of the University Hospitals ethical committee and obtaining a written consent from every included patient, during the study period from $1^{\text {st }}$ of March, 2016 to $1^{\text {st }}$ of April, 2017. Any patients with CKD at any stage from both sexes were involved in this study, but those with end stage renal disease or on renal replacement therapy were excluded.CKD is defined as: 1) kidney damage $\geq 3$ months, as defined by functional or structural abnormalities of the kidney with or without decreasing GFR, manifest by either: pathological abnormalities or markers of kidney damage, involving abnormal blood or urine composition or imaging abnormalities; 2) GFR $<60 \mathrm{ml} / \mathrm{min} / 1.73 \mathrm{~m}^{2}$ for $\geq 3$ months, with or without kidney damage (Levey et al.,2003). History including smoking history and the presence of any associated comorbidities, anthropometric measurements (weight, height and body mass index), through clinical examination, abdominal ultrasound examination were done for every included patient.

\section{Biochemical measurements}

Venous blood samples $(5 \mathrm{cc})$ were taken from the included patients. Serum separator tubes were used and samples were allowed to be clotted for 30 minutes before centrifugation for 15 minutes at $3500 \mathrm{rpm}$. Serum of each sample was transferred and divided into three aliquots using $1 \mathrm{ml}$ cryotubes and stored at $-20{ }^{\circ} \mathrm{C}$ till time of biochemical assays. All samples were measured in a single assay to avoid repeated freeze-thaw cycles. Colorimetric assays of serum phosphorus, calcium, urea and creatinine were measured, using Cobas c311automated chemistry analyzer, Roche Diagnostics, Germany, while, parathormone hormone and FGF23, were measured by ELISA Multiskan EX Microplate Photometer [STAT FAX-2100; Thermo Scientific, USA, using commercially available ELISA assay Kits(supplied by BT Bioassay technology, Shanghai Korain Biotech Co., LTD, China, catalog No.:E1055Huand Chongqing Biopes Co., LTD, China, catalog No.: BYEK1601), these kits were based on standard sandwich enzymelinked immune-sorbent assay technology. Estimated glomerular filtration rate of every included patient was calculated by using Mayo Clinic Quadratic Equation (MCQE) 14.10 Assessment of CKD grade was done as prescribed by Levey et al (2003).

\section{Statistical analysis}

The collected data were revised, organized, tabulated and statistically analyzed using statistical package for social sciences (SPSS) version 23.0 for windows. Data are presented as the mean \pm standard deviation (SD), frequency, and percentage. Categorical variables were compared using the chi-square $\left(\chi^{2}\right)$ and Fisher's exact tests. Continuous normally distributed variables were compared using the Student t test (two-tailed). Mann-Whitney U test was used for comparison of nonparametric continuous variables. Pearson and Kendall's tau correlations analysis were used to assess the bivariate correlations between variables. ROC curve was used to determine the cutoff points. The level of significance was considered when the $p$ value $<0.05$.

\section{Results:-}

The mean age of the included patients was 56.8 years old \pm 13 SD with their mean BMI was 28.4 \pm 5 . Females represent the majority of cases (79\%), smokers were 31\%,69\% of the study group were hypertensive (the mean 
systolic diastolic blood pressure were $131 \mathrm{mmHg} \pm 16 \mathrm{SD}$ and $78.2 \mathrm{mmHg} \pm 8 \mathrm{SD}$ respectively) and $65 \%$ were diabetic.

Regarding the abdominal ultrasound findings of the included patients, $93 \%$ of cases have medically diseased kidney, while, $5 \%$ have polycystic kidney and 3\% have bilaterally obstructed kidneys. Regarding the relative frequency of various grades of the CKD of the included patients, grade 1, 2, 3a, 3b, 4, 5 were 17\%, 19\%, 3\%, 39\%, $13 \%$ and 9\% respectively. The mean $\pm \mathrm{SD}$ of the measured biochemical parameters were presented in (Table 1).

Table 1:-The mean $\pm \mathrm{SD}$ of the serum levels of the measured biochemical parameters among CKD-MBD patients in comparison with the reference range.

\begin{tabular}{|l|c|c|}
\hline Variables & Mean \pm SD & $\begin{array}{c}\text { Reference } \\
\text { Range }\end{array}$ \\
\hline Urea $(\mathbf{m g} / \mathbf{d l})$ & $75.5 \pm 35$ & $15-45$ \\
\hline Creatinine (mg/dl) & $2.2 \pm 1.2$ & $\mathrm{M}=0.7-1.1$ \\
& $\mathrm{~F}=0.6-1.3$ \\
\hline Total calcium (mg/dl) & $7.8 \pm 1.1$ & $8.2-10.7$ \\
\hline Phosphorous (mg/d) & $4.2 \pm 1.1$ & $2.5-4.5$ \\
\hline Parathormone hormone (pg/ml) & $134 \pm 120$ & $12-72$ \\
\hline eGFR (ml/min) & $52 \pm 25.6$ & Calculated $^{10}$ \\
\hline FGF23(pg/ml) & $9.7 \pm 8$ & $0.69-1.8$ \\
\hline
\end{tabular}

Regarding the serum FGF23 levels in relation to CKD grade, this was shown in (Table 2 and Figure 1), which revealed a more frequent abnormally high serum FGF23 among CKD grade $3 \& 4$ compared to other grades. Also there was significant positive correlation between the serum FGF234 levels and the CKD grade $(\mathrm{r}=0.21, p=0.03)$.

Table 2:-Relation between serum levels of FGF23 versus CKD grades

\begin{tabular}{|c|c|c|c|c|}
\hline \multirow[t]{2}{*}{ CKD grades } & \multicolumn{2}{|c|}{ Serum FGF23 } & \multirow[t]{2}{*}{$\mathbf{X}^{2}$} & \multirow[t]{2}{*}{$P$ value } \\
\hline & Norm & lormal* & & \\
\hline Grade 1 & $8(33.3 \%)$ & $9(11.8 \%)$ & \multirow[t]{6}{*}{13.2} & \multirow[t]{6}{*}{$0.01^{*}$} \\
\hline Grade 2 & $8(33.3 \%)$ & $11(14.5 \%)$ & & \\
\hline Grade 3a & 0 & $3(3.9 \%)$ & & \\
\hline Grade 3b & $6(25 \%)$ & $33(43.9 \%)$ & & \\
\hline Grade 4 & $1(4.2 \%)$ & $12(15.8 \%)$ & & \\
\hline Grade 5 & $1(4.2 \%)$ & $8(10.5 \%)$ & & \\
\hline
\end{tabular}

*Abnormal means elevated serum levels in comparison with the reference range

$* * p$ value considered to be significant when $<0.05$. 


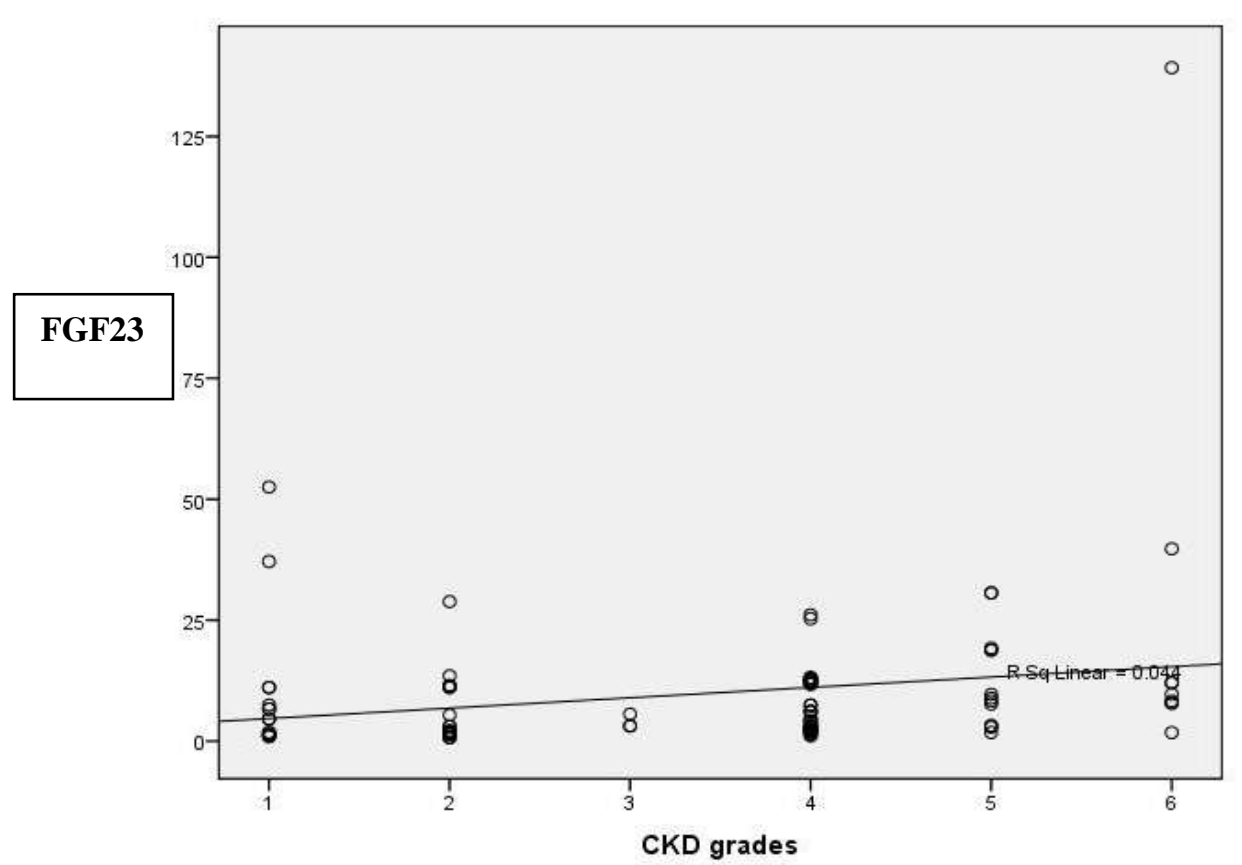

Figure 1:-Correlation between CKD grades versus serum FGF23 levels.

The correlations between the serum FGF23 levels vs. other measured biochemical parameters have been presented in (Table 3), which revealed significant positive correlations between serum levels of FGF23 vs. both urea and PTH $(\mathrm{r}=0.19, \mathrm{p}=0.04$ and $\mathrm{r}=0.31, \mathrm{p}=0.002$ respectively) with significant negative correlations between serum FGF23 levels vs. both total calcium and eGFR ( $\mathrm{r}=-0.21, \mathrm{p}=0.02$ and $\mathrm{r}=-0.39, \mathrm{p}=0.0001$ respectively). There were nonsignificant correlations between serum FGF23 and age, weight, height, BMI and phosphorous ( $>>0.05$ ).

Table 3:-Correlations between serum FGF23 levels versus urea, creatinine, calcium, phosphorous, PTH and eGFR among CKD-MBD patients.

\begin{tabular}{|l|c|c|}
\hline \multicolumn{1}{|c|}{ Variables } & \multicolumn{2}{c|}{ FGF23 } \\
\hline Urea $(\mathbf{m g} / \mathbf{d l})$ & 0.19 & $0.04^{*}$ \\
\hline Creatinine (mg/dl) & 0.03 & 0.56 \\
\hline Total calcium (mg/dl) & -0.21 & $0.02^{*}$ \\
\hline Phosphorous (mg/dl) & 0.07 & 0.47 \\
\hline Parathormone hormone (pg/ml) & 0.31 & $0.002^{*}$ \\
\hline eGFR (ml/min) & -0.39 & $0.0001^{*}$ \\
\hline
\end{tabular}

${ }^{*} p$ value considered to be significant when $<0.05$.

Validity of FGF23 in early prediction of altered serum calcium and phosphorous among CKD patients for early pick up CKD-MBD was shown in (Table 4 and Figure 2). This demonstrate that serum FGF23 can be considered as better negative than positive in predicting CKD-MBD among CKD patients. The cut off point for detecting abnormal calcium level was $2.9 \mathrm{pg} / \mathrm{ml}$ and $3.1 \mathrm{pg} / \mathrm{ml}$ for abnormal serum phosphorous level with sensitivity ( $76 \%$, $63 \%$ respectively) and specificity (45\% and $44 \%$ respectively), PPV (55\%, 57\% respectively) and NPP (80\%, 70\% respectively).

Table 4:-Validity of serum FGF23 in prediction of altered serum calcium and phosphorous among CKD patients.

\begin{tabular}{|c|c|c|}
\hline Validity & Calcium & Phosphorous \\
\hline Best cut off & 2.9 & 3.1 \\
\hline AUC & 0.61 & 0.55 \\
\hline Sensitivity & $76 \%$ & $63 \%$ \\
\hline Specificity & $45 \%$ & $44 \%$ \\
\hline
\end{tabular}




\begin{tabular}{|c|c|c|}
\hline PPV & $55 \%$ & $57 \%$ \\
\hline NPV & $80 \%$ & $70 \%$ \\
\hline Accuracy & $61 \%$ & $55 \%$ \\
\hline
\end{tabular}
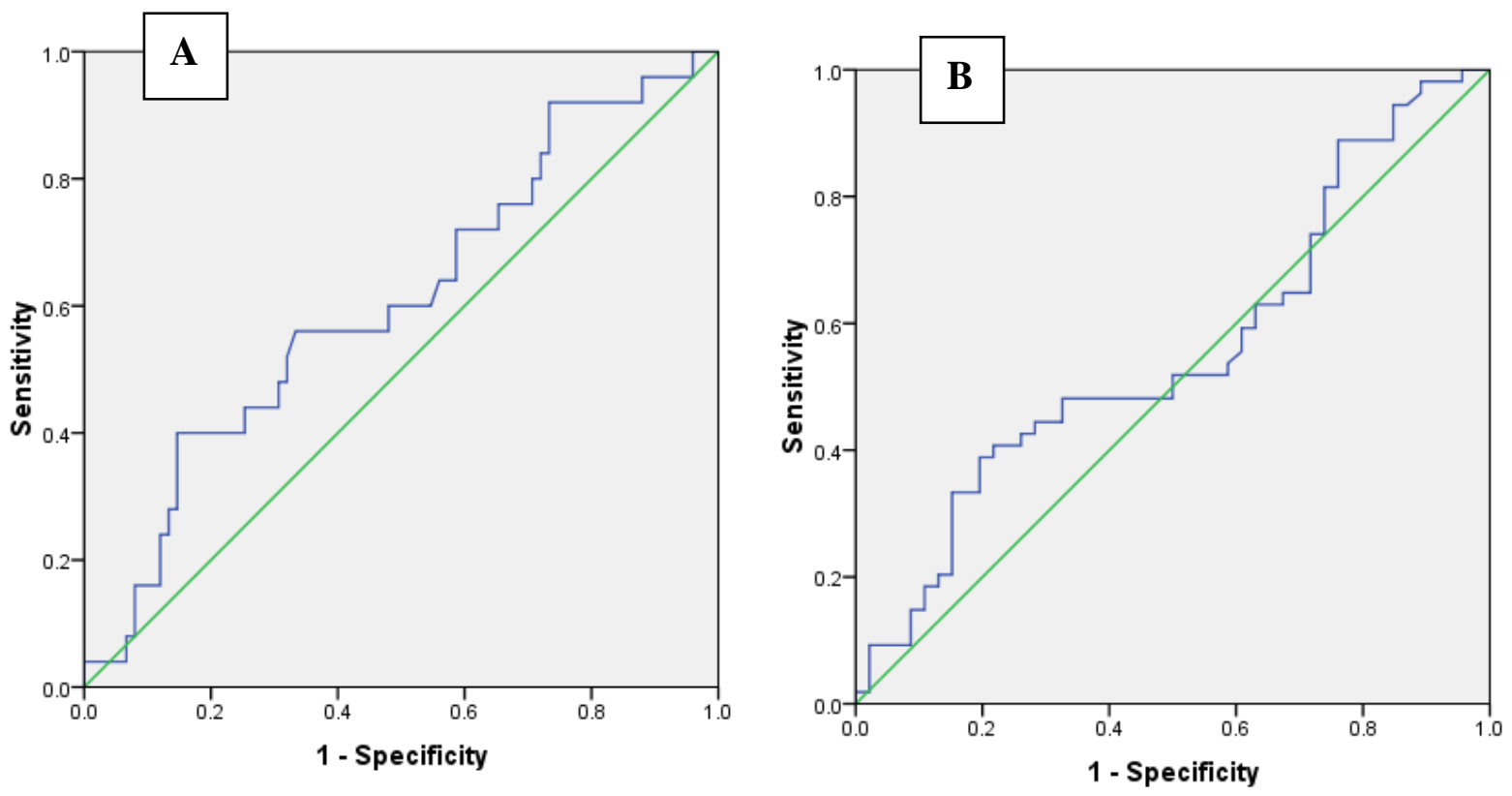

Figure 2:- Receiver operating characteristic curve for serum FGF23 levels in predicting abnormal serum calcium levels (A) and phosphorous levels (B) in CKD patients.

\section{Discussion:-}

Understanding the contributory role of increased FGF23 and secondary hyperparathyroidism to changes in minerals and bone metabolism among CKD patients is a challenge (Tentori et al.,2008).

The findings of the present study demonstrate elevated serum levels of urea, creatinine, phosphorous, PTH with decreased eGFR and calcium in comparison to the reference range. These findings were in agreement with various cross sectional studies (Larsson et al., 2003; Gutierrez et al.,2005). Although the exact CKD grade at which FGF23 become firstly significantly elevated differed across studies (Wolf, 2012), but in agreement with our results as regard the higher frequency of elevated serum FGF23 among the included CKD grade 3 and 4,Tsai et al (2016) reported similar findings.

FGF23 could be considered as a kidney function biomarker, thus adults with higher FGF23 may be at greater risk of CKD (Semba et al.,2012). The significant positive correlation of FGF23 with CKD grade confirmed in the present study supports the predictive value of FGF23 in CKD progression, reflecting its possible role in CKD pathogenesis that need to be confirmed by further molecular researches.

It is well known that CKD induces a decrease in the glomerular filtration rate with subsequent reduction in the excretion of phosphorous, resulting in an increase in the serum FGF23 level to increased phosphorous excretion in urine and decreased its intestinal and renal tubular reabsorption via suppressing renal 1- $\alpha$ hydroxylase, all these events occurs early in CKD often before a rise in serum phosphorous levels (Isakova et al.,2011; Russo and Battaglia, 2011). The present study revealed significant positive correlation between serum FGF23 with both urea and PTH and significant negative correlations between its serum level with both total calcium and eGFR. Although there was positive correlation between FGF23 and phosphorous, but not reach to a significant level, that could be explained by the early rise of FGF23 even before rise in the phosphorous level or by the relatively small sample size included in the present study. In accordance with our findings, a study done by Chathoth et al (2015). Also, in 
agreement with our findings, Semba et al (2012), who reported significant positive correlation between FGF23 and PTH, Yaghoubi et al (2016), reported non-significant correlations between FGF23 with age, sex, phosphorous, BMI but in disagreement with this study, they found a non-significant correlation between FGF23 with calcium levels, Liu et al (2017), reported significant negative correlation between FGF23 and eGFR.

The literature research regarding the cut off point of serum FGF23 in early predicting minerals disturbances in CKD patients is seldom. The present study revealed that FGF23 is better negative than positive predictive biomarker for calcium and phosphorous disturbances in CKD patients at cut off point 2.9 and $3.1 \mathrm{pg} / \mathrm{ml}$ respectively.

\section{Conclusions:-}

This confirmatory study proves the importance of FGF23 as an emerging biomarker in CKD that could early predict the occurrence of CKD-MBD even before significant alteration in serum phosphorous, calcium or PTH. FGF23 could be researched as effective targeted therapeutic approach in CKD patients.

\section{Statement of conflict of interest:-}

The authors declare no conflict of interest. The authors alone are responsible for the content of this manuscript.

\section{References:-}

1. Wolf M (2012). Update on fibroblast growth factor 23 in chronic kidney disease. Kidney Int 82:737-747.

2. Moe S, Drueke T, Cunningham J, et al (2006). Definition, evaluation, and classification of renal osteodystrophy: a position statement from Kidney Disease: Improving Global Outcomes (KDIGO). Kidney Int 69(11):1945-53.

3. Silver J, Rodriguez M, Slatopolsky E (2012). FGF23 and PTH: double agents at the heart of CKD. Nephrol. Dial. Transplant 27: 1715-1720 .

4. Diniz H, Frazão JM (2013). The role of fibroblast growth factor 23 in chronic kidney disease-mineral and bone disorder.Nefrologia13;33:835-44

5. Liu S, Zhou J, Tang W, et al (2006). Pathogenic role of Fgf23 in Hyp mice. Am J Physiol Endocrinol Metab 291:38-49.

6. Komaba H (2010). CKD-MBD (Chronic Kidney Disease-Mineral and Bone Disorder).Role of FGF23-Klotho axis in CKD-MBD .Clin Calcium20:1028-1036.

7. Nakai K, Komaba H, Fukagawa M (2010). New insights into the role of fibroblast growth factor 23 in chronic kidney disease. J Nephrol23:619-625.

8. Olauson H, Vervloet MG, Cozzolino M, et al (2014). New insights into the FGF23-Klotho axis.Semin Nephrol34: 586-597

9. Levey A, Coresh J, Balk E, et al (2003). National kidney foundation practice guidelines for chronic kidney disease: evaluation, classification, and stratification. Ann Intern Med 139:137-147.

10. Raju D, Lalitha D, Kiranmayi P (2012). Observation of estimated GFR in the assessment of chronic kidney disease: application and practice. Asian J Pharm Clin Res 5: 201-206.

11. Tentori F, Blayney MJ, Albert JM, et al (2008). Mortality risk for dialysis patients With different levels of serum calcium, phosphorus, and PTH: the dialysis outcomes and practice patterns study (DOPPS).American Journal of Kidney Diseases 52: 519-530.

12. Larsson T, Nisbeth U, Ljunggren O, et al (2003). Circulating concentration of FGF-23 increases as renal function declines in patients with chronic kidney disease, but does not change in response to variation in phosphate intake in healthy volunteers. Kidney Int 64:2272-2279

13. Gutierrez O, Isakova T, Rhee E, et al (2005). Fibroblast growth factor-23 mitigates hyperphosphatemia but accentuates calcitriol deficiency in chronic kidney disease. J Am Soc Nephrol 16:2205-2215.

14. Tsai MH, Leu JG, Fang YW, et al (2016). High Fibroblast Growth Factor 23 Levels Associated With Low Hemoglobin Levels in Patients With Chronic Kidney Disease Stages 3 and 4. Medicine 95:e3049.

15. Semba RD, Fink JC, Sun K, et al (2012). Serum Fibroblast Growth Factor-23 and Risk of Incident Chronic Kidney Disease in Older Community-Dwelling Women. CJASN 7:85-91.

16. Isakova $\mathrm{T}$, Xie H, Yang W, et al (2011). Fibroblast growth factor 23 and risks of mortality and end-stage renal disease in patients with chronic kidney disease. JAMA. 305: 2432-2439.

17. Russo D, Battaglia Y (2011). Clinical significance of FGF-23 in patients with CKD. Int J Nephrol 2011: 364890 . 
18. Chathoth S, Al-Mueilo S, Cyrus C, et al (2015). Elevated Fibroblast Growth Factor 23 Concentration: Prediction of Mortality among Chronic Kidney Disease Patients. Cardiorenal Medicine 6:73-82.

19. Yaghoubi F, Ahmadi F, Lesanpezeshki M, et al (2016). A study on the association of serum fibroblast growth factor-23 with various indices of chronic kidney disease patients not yet on dialysis. Journal of Renal Injury Prevention 5:104-107.

20. Liu D, Alvarez-Elías AC, Wile B, et al (2017). Deviations from the expected relationship between serum FGF23 and other markers in children with CKD: a cross-sectional study. BMC Nephrology 18:204. 